\title{
A Study of Mental Health and Psychological Well Being among Teachers and Lecturers
}

\author{
Sama Afsana $\mathrm{A}^{1 *}$
}

\section{ABSTRACT}

The main purpose of this research was to find out the mean difference between teachers and lecturers in mental health and psychological well-being. The total sample consisted of 120 teachers and lecturers. The research tools for mental health scale was measured by Dr. A. K. Shreevastav and Dr. Jagdish and the psychological well-being scale was measured by Bhogle and Prakash (1995).The ' $t$ ' test is applied to check the significance of mental health and psychological well-being in teachers and lecturers to check the method which was used for test. The result shows, there is no significant difference between teachers and lecturers in mental health and psychological well-being.So, the hypothesis is accepted.

Keywords: Mental Health, Psychological Well-Being

Mental health includes our emotional, psychological, and social well-being. It affects how we think, feel, and act. It also helps determine how we handle stress, relate to others, and make choices. Mental health is important at every stage of life, from childhood and adolescence through adulthood.

Mental health is a level of psychological well-being, or an absence of a mental disorder; ${ }^{[1]}$ it is the "psychological state of someone who is functioning at a satisfactory level of emotional and behavioral adjustment" From the perspective of positive psychology or holism, mental health may include an individual's ability to enjoy life, and create a balance between life activities and efforts to achieve psychological resilience. According to World Health Organization (WHO) mental health includes "subjective well-being, perceived self-efficacy, autonomy, competence, intergenerational dependence, and self-actualization of one's intellectual and emotional potential, among others."WHO further states that the well-being of an individual is encompassed in the realization of their abilities, coping with normal stresses of life, productive work and contribution to their community. However, cultural differences, subjective assessments, and competing professional theories all affect how "mental health" is defined.

\footnotetext{
${ }^{1}$ Research Scholar, Psychology Department, Maharaja Krishnakumarsinhji Bhavnagar University, Bhavnagar, Gujarat

*Responding Author

(c) 2016 I S Afsana; licensee IJIP. This is an Open Access Research distributed under the terms of the Creative Commons Attribution License (http://creativecommons.org/licenses/by/2.0), which permits unrestricted use, distribution, and reproduction in any Medium, provided the original work is properly cited.
} 
Mental health is also used as a consumerist euphemism for mental illness, especially when used in conjunction with "concerns", "problems", or "clinic". Consequently, "mental health" is now being equated with mental illness without reference to the positive strengths associated with mental health, as above. Similarly, the term "behavioral health" is being used, incorrectly, to refer to mental illness, as a consumerist approach to avoiding the stigma associated with the words "mental" and "illness". Consequently, some mental illness clinics are now identified by the inaccurate phrase behavioral wellness.

A person struggling with his or her mental health may experience stress, depression, anxiety, relationship problems, grief, addiction, ADHD or learning disabilities, mood disorders, or other mental illnesses of varying degrees. Therapists, life coaches, psychologists, nurse practitioners or physicians can help manage mental illness with treatments such as therapy, counseling, or medication.

Counselors who are trained and experienced in psycho-therapeutic techniques can treat patients. Psychiatrists may need to be involved during the treatment process. It is to be noted that psychotherapists cannot prescribe psychotic drugs, only a psychiatrist can.

The new field of global mental health is "the area of study, research and practice that places a priority on improving mental health and achieving equity in mental health for all people worldwide."

The literature on psychological well-being has progressed rapidly since the emergence of the field over five decades ago. As recent surveys show psychologists and other social scientists have taken huge steps in their understanding of the factors influencing psychological/ subjective well-being.

Psychological well-being refers to how people evaluate their lives. According to Diener (1997), these evaluations may be in the form of cognitions or in the form of affect. The cognitive part is an information based appraisal of one's life that is when a person gives conscious evaluative judgments about one's satisfaction with life as a whole. The affective part is a hedonic evaluation guided by emotions and feelings such as frequency with which people experience pleasant/unpleasant moods in reaction to their lives. The assumption behind this is that most people evaluate their life as either good or bad, so they are normally able to offer judgments. Further, people invariably experience moods and emotions, which have a positive effect or a negative effect. Thus, people have a level of subjective well-being even if they do not often consciously think about it, and the psychological system offers virtually a constant evaluation of what is happening to the person.

In this paper we have defined psychological well-being in terms of internal experience of the respondent and their own perception of their lives. We focused both on momentary moods and long term states of their mental well-being. 
Current social indicators can capture phenomena such as crime, divorce, environmental problems, infant mortality, gender equality, etc. Thus, they can capture aspects of quality of life that add to the description drawn by economic indicators. However, these social indicators fail to capture the subjective well-being of people because they do not reflect the actual experiences such as the quality of relationships, the regulation of their emotions and whether feelings of isolation and depression pervade in their daily life. On the other hand, economic indicators fail to include side effects and the tradeoffs of market production and consumption. For example, the environmental costs of industries certainly are not observed from the national accounts. Another disadvantage of economic and social measures in terms of their links to psychological well-being is that they are based on models of rational choice, whereby people follow a set of logical rules when making development plans. However, works by Kahneman (1994) in psychology and economics reveal that people do not always make rational choices, and that these choices do not necessarily enhance psychological well-being.

\section{What Is Mental Health?}

Good mental health is a sense of well-being confidence and self esteem it enables us to fully enjoy and appreciate other people day to day life and environment when we are mentally health we can,

- $\quad$ From positive relationships.

- $\quad$ Use our abilities to reach our potentate.

- $\quad$ Deal with life challenges.

World mental health day is observed on $10^{\text {th }}$ October every year with the overall objective of revising awareness of mental health issues around the world and mobilizing efforts support of mental health.

Mental health includes our emotional, psychological, and social well-being. It affects how we think, feel, and act. It also helps determine how we handle stress, relate to others, and make choices. Mental health is important at every stage of life, from childhood and adolescence through adulthood.

Over the course of your life, if you experience mental health problems, your thinking, mood, and behavior could be affected. Many factors contribute to mental health problems, including:

- $\quad$ Biological factors, such as genes or brain chemistry

- $\quad$ Life experiences, such as trauma or abuse

- $\quad$ Family history of mental health problems

Mental health problems are common but help is available. People with mental health problems can get better and many recover completely.

\section{What Is Well-Being?}

Psychological well-being leads to desirable outcomes, even economic ones, and does not necessarily follow from them. In a very intensive research done by Dianer and his colleagues, 
people who score high in psychological well-being later earn high income and perform better at work then people who score low in well-being. It is also found to be related to physical health. In addition, it is often noticed that what a society measures will in turn influence the things that it seeks. If a society takes great effort to measure productivity, people in the society are likely to focus more on it and sometimes even to the detriment of other values. If a society regularly assesses well-being, people will provide their attention on it and learn more about its causes. Psychological well-being is therefore valuable not only because it assesses well-being more directly but it has beneficial consequences.

Well-being is multidimensional, and not merely about happiness, or positive emotions. A good life is balanced and whole, engaging each of the different aspects of well-being, instead of being narrowly focused. Ryff roots this principle in Aristotle's Nichomachean Ethics, where the goal of life isn't feeling good, but is instead about living virtuously

Carol Ryff's six categories of well-being are:

\section{1) Self-Acceptance}

High Self Acceptance: You possess a positive attitude toward yourself; acknowledge and accept multiple aspects of yourself including both good and bad qualities; and feel positive about your past life.

Low Self Acceptance: You feel dissatisfied with yourself; are disappointed with what has occurred in your past life; are troubled about certain personal qualities; and wish to be different than what you are.

\section{2) Personal Growth}

Strong Personal Growth: You have a feeling of continued development; see yourself as growing and expanding; are open to new experiences; have the sense of realizing your potential; see improvement in yourself and behavior over time; are changing in ways that reflect more selfknowledge and effectiveness.

Weak Personal Growth: You have a sense of personal stagnation; lack the sense of improvement or expansion over time; feel bored and uninterested with life; and feel unable to develop new attitudes or behaviors.

\section{3) Purpose in Life}

Strong Purpose in Life: You have goals in life and a sense of directedness; feel there is meaning to your present and past life; hold beliefs that give life purpose; and have aims and objectives for living.

Weak Purpose in Life: You lack a sense of meaning in life; have few goals or aims, lack a sense of direction; do not see purpose of your past life; and have no outlook or beliefs that give life meaning. 


\section{4) Positive Relations With Others}

Strong Positive Relations: You have warm, satisfying, trusting relationships with others; are concerned about the welfare of others; are capable of strong empathy, affection, and intimacy; and understand the give and take of human relationships.

Weak Relations: You have few close, trusting relationships with others; find it difficult to be warm, open, and concerned about others; are isolated and frustrated in interpersonal relationships; and are not willing to make compromises to sustain important ties with others.

\section{5) Environmental Mastery}

High Environmental Mastery: You have a sense of mastery and competence in managing the environment; control complex array of external activities; make effective use of surrounding opportunities; and are able to choose or create contexts suitable to your personal needs and values.

Low Environmental Mastery: You have difficulty managing everyday affairs; feel unable to change or improve surrounding contexts; are unaware of surrounding opportunities; and lack a sense of control over the external world.

\section{6) Autonomy}

High Autonomy: You are self-determining and independent; are able to resist social pressures to think and act in certain ways; regulate behavior from within; and evaluate yourself by personal standards.

Low Autonomy: You are concerned about the expectations and evaluations of others; rely on judgments of others to make important decisions; and conform to social pressures to think and act in certain ways.

\section{OBJECTS OF STUDY:}

To study of mental health and psychological well - being among teachers and lecturers.

\section{Hypothesis Of Study:}

- There is no significant difference between the teachers and lecturers for their mental health and psychological well-being.

\section{Research Methodology:}

- Sample :-

Sample in this study consist 120 subjects having 60 teachers and 60 lecturers from Bhavnagar city.

\section{- Variable :-}

\section{$>\quad$ Independent variables :-}

I. Teachers

II. Lecturers 
$>\quad$ Dependent Variable :-

I. Mental Health

II. Psychological well-being

\section{- Tools :-}

\section{Personal Data Sheet}

A personal datasheet developed by the investigator was used to collect information about types of teachers and lecturers.

\section{Mental Health Inventory}

The mental health consented and standardized by A.K shreevastav and Dr. Jagdish used from the study. This scale reliability 0.73 and validity of 0.54 .

\section{Psychological well-being}

Psychological well-being questionnaire by Bhogle and Prakash (1995), was used to measure psychological well-being. The questionnaire contains 28 items with true and false response alternative.

\section{Statistical Analysis :-}

In this study ' $\mathrm{t}$ ' test was used for statistical Analysis to find out the aim.

\section{RESULT AND DISCUSSION}

't' ratio of the mental Health and psychological well-being between teachers and lecturers.

\begin{tabular}{|l|l|l|l|l|l|l|}
\hline Variables & Group & N & M & SD & t & $\begin{array}{l}\text { Level of } \\
\text { significant }\end{array}$ \\
\hline \multirow{2}{*}{ Mental Health } & Teachers & 30 & 41.03 & 9.79 & 0.53 & N.S \\
\cline { 2 - 6 } & Lecturers & 30 & 52.33 & 4.37 & & \\
\hline $\begin{array}{l}\text { Psychological } \\
\text { well-being }\end{array}$ & Teachers & 30 & 20.07 & 4.14 & 0.70 & N.S \\
\cline { 2 - 5 } & Lecturers & 30 & 20.03 & 3.31 & & \\
\hline
\end{tabular}

The above table shows the mean difference between four groups in terms of mental health .The mean for the Teachers is 41.03 and SD 9.79 as well the mean of lecturers is 52.33 and SD 4.37.the obtained ' $\mathrm{t}$ ' is 0.53 that is significant difference. And also this table show the mean difference between two groups in terms of psychological well-being. The mean for the teacher is 20.07 and SD 4.14 as well the mean of lecturers is 20.03 and SD 3.31,the obtained ' $t$ ' is 0.70 that is no significant difference. This result accepted the hypothesis that "There is no significant difference between the teachers and lecturers for their mental health and well-being.

\section{CONCLUSION}

There is no significant difference between the teachers and lecturers for their mental health and psychological well-being. 


\section{REFERENCE}

Bhogle,S and Jay Prakash,I.,(1995),Development of the psychological well being questionnaire, Journal of Personality and Clinical studies,Vol.11(1\&2),PP,5-9.

Dhillon,P.K.,and Jasra, A. (1992).Personality, anxiety and self-concept. A study across age variation and social class. In P.K Dhillon (Eds)Psychological aspects of aging in India (PP.119-136).New Delhi; concept publishing.

Douglas, C. K,(1980).Adulthood and ageing. Canada. Johan Wiley and sons.

Graham Michael C.(2014)facts of life, ten issues of contentment out skirts press P no 6-10.

Johda, M.(1958).current concepts of positive mental health. New York: Basic books.

Kitchener B,A yorm.AF,2002,mental health first Aid manual centre for mental health research Canberra P.S.

Patel V. Prince m.2020 Global mental health- a new global health field comes of age.yama,303,1976-1977.

Richards K.C Campania C. muse burke Y.L (2010) "self-care and well-being in mental health professionals the mediating effects of self awareness and mindfulness "mental health counseling 32.

How to cite this article: S Afsana (2016), A Study of Mental Health and Psychological Well Being among Teachers and Lecturers, International Journal of Indian Psychology, Volume 3, Issue 3, No. 8, DIP: 18.01.137/20160303, ISBN: 978-1-365-12176-0 